\title{
The Role of Teachers in The Development of National Characters in Religion Based School: a Case Study In SD Muhammadiyah 3 Nusukan Surakarta Indonesia
}

\section{Roy Ardiansyah}

Universitas Sebelas Maret

royardiansyah@staff.uns.ac.id

\section{Article History}

accepted 24/09/2019

\begin{abstract}
The phenomenon of the spread of religious-based elementary schools in the community will certainly have an impact on the development of the Indonesian Human Resources Development Index. This includes efforts to strengthen the National Character. The purpose of this study is to describe the role of teachers in religion-based elementary schools in strengthening the national character of students. This research uses a qualitative approach. The subjects of this study were 37 students and teachers. Data collection techniques used in this study were participant observation, in-depth interviews, literacy studies, and questionnaires. Analysis of the data used is Miles and Huberman Interactive Analysis. The results showed that teachers have an important role in strengthening the Nationality Character in Religion-Based Primary Schools, namely (1) Teachers not only teach about concepts but also emulate them, (2) Provide effective communication media between students and parents, (3) and supervise every student's behavior.
\end{abstract}

Keywords: National Characters, Religion Based School, Surakarta

\begin{abstract}
Abstrak
Fenomena penyebaran sekolah dasar berbasis agama di masyarakat tentunya akan berdampak pada perkembangan Indeks Pengembangan Sumber Daya Manusia Indonesia. Ini termasuk upaya untuk memperkuat Karakter Nasional. Tujuan dari penelitian ini adalah untuk menggambarkan peran guru di sekolah dasar berbasis agama dalam memperkuat karakter nasional siswa. Penelitian ini menggunakan pendekatan kualitatif. Subjek penelitian ini adalah 37 siswa dan guru. Teknik pengumpulan data yang digunakan dalam penelitian ini adalah observasi partisipan, wawancara mendalam, studi literasi, dan kuesioner. Analisis data yang digunakan adalah Miles and Huberman Interactive Analysis. Hasil penelitian menunjukkan bahwa guru memiliki peran penting dalam memperkuat Karakter Kebangsaan di Sekolah Dasar Berbasis Agama, yaitu (1) Guru tidak hanya mengajarkan tentang konsep tetapi juga meniru mereka, (2) Menyediakan media komunikasi yang efektif antara siswa dan orang tua, (3) ) dan mengawasi perilaku setiap siswa.

Kata Kunci: Karakter Nasional, Sekolah Berbasis Agama, Surakarta
\end{abstract}

Social, Humanities, and Education Studies (SHEs): Conference Series https://jurnal.uns.ac.id/shes

p-ISSN 2620-9284

e-ISSN 2620-9292 


\section{PENDAHULUAN}

Perdamaian merupakan cita-cita yang dimiliki oleh semua bangsa di dunia. Perdamaian dapat terwujud apabila adanya rasa toleransi, saling menghargai, saling melindungi, dan lain sebagainya yang merupakan karakter yang melekat pada masing-masing Individu. Karakter yang dimiliki oleh seseorang akan memberikan andil yang besar pada terciptanya sebuah perdamaian.

Salah satu tolok ukur atau indikator karakter dapat dilihat pada Indeks Pembangunan Manusia (IPM). Indeks Pembangunan Manusia Indonesia menurut data terbaru menunjukkan adanya peningkatan tetapi tetap terdapat kesenjangan. Berdasarkan data dari United Nations Development Programme (UNDP) Indonesia menempati peringkat 4 negara dengan perkembangan yang signifikan, namun secara akumulatif masih berada di peringkat 113. Kesenjangan yang terjadi apabila dilihat dari beberapa fenomena yang terjadi di lingkungan masyarakat saat ini mengindikasikan adanya degradasi karakter kebangsaan karena beberapa faktor seperti konflik kepentingan dan isu SARA.

Karakter Kebangsaan memiliki peranan penting dalam menentukan masa depan bangsa. Oleh karenanya penguatan karakter kebangsaan di tengah masyarakat harus diperkuat, karena pada hakikatnya karakter kebangsaan yang dimiliki oleh setiap individu akan berdampak pada keberhasilannya. Hakikatnya karakter adalah usaha manusia untuk belajar mengatasi dan memperbaiki kelemahan, sekaligus membawa yang baru kebiasaan positif (Purwati \& Kusniarti, 2016). Kebiasaan positif ini nantinya yang akan membuat seseorang memiliki perilaku yang sesuai dengan norma yang ada, serta secara sadar akan selalu melakukan self evaluation terhadap perilaku yang dilakukan.

Pendidikan merupakan cara yang tepat dan efisien untuk menginternalisasikan Karakter Kebangsaan kepada generasi penerus bangsa. Sebagaimana telah di amanahkan di dalam UU No 20 Tahun 2003 tentang Sistem Pendidikan Nasional bahwa pendidikan Nasional memiliki tujuan sebagai berikut "Pendidikan nasional berfungsi mengembangkan kemampuan dan membentuk watak serta peradaban bangsa yang bermartabat dalam rangka mencerdaskan kehidupan bangsa, bertujuan untuk berkembangnya potensi peserta didik agar menjadi manusia yang beriman dan bertakwa kepada Tuhan Yang Maha Esa, berakhlak mulia, sehat, berilmu, cakap, kreatif, mandiri, dan menjadi warga negara yang demokratis serta bertanggung jawab". Berdasarkan landasan yuridis tersebut dapat dimaknai bahwa sistem pendidikan Indonesia memiliki cita-cita membentuk manusia Indonesia yang berpengetahuan tetapi juga memiliki karakter kebangsaan yang baik. Selain itu, tujuan pendidikan Indonesia juga selaras dengan empat pilar yang diterbitkan oleh UNESCO yakni (1) Learning To Know, (2) Learning to do, (3) Learning to be, dan (4) Learning to live together. Dari empat pilar ini dapat dimaknai bahwa pendidikan globalpun tidak menghendaki pembentukan manusia hanya dari segi berpengetahuan baik tetapi juga mampu berkontribusi dimasyarakat dalam bentuk minimal berkarakter yang baik.

Bahwa terdapat dua tujuan besar di dalam pelaksanaan pendidikan yakni menjadikan siswa pintar dan menjadi siswa baik, "down through history, in countries all over the world, education has had two great goals: to help young people become smart and to help them become good"(Lickona, 1992). Maknanya adalah penguatan karakter didalam pembelajaran menjadi penting karena seseorang yang berilmu tanpa dibekali dengan karakter yang baik tidak akan sempurna kompetensi yang dimiliki.

Pendidikan Karakter menjadi fokus utama dari pelaksanaan pendidikan Indonesia. Kurikulum 2006 menjadi pelopor keseriusan pendidikan Indonesia untuk membangun karakter manusia Indonesia. Kurikulum 2006 atau Kurikulum Tingkat Satuan Pendidikan (KTSP) telah menerbitkan 18 karakter yang harus dimiliki oleh siswa yakni religius, jujur, toleransi,disiplin, kerja keras, kreatif, mandiri, demokratis, 
rasa ingin tahu, semangat kebangsaan, cinta tanah air, menghargai prestasi, bersahabat komunikatif, cinta damai, gemar membaca, peduli lingkungan, peduli sosial, dan tanggungjawab. Delapan Belas Karakter inilah yang dimaksud dengan karakter kebangsaan.

Karakter Kebangsaan ini wajib berikan dan dibentuk disetiap institusi pendidikan. Pembentukan Karakter Kebangsaan bukan hanya menajdi tanggung jawab dari sekolah yang berada di bawah pemerintah atau sekolah negeri melainkan menjadi tanggung jawab semua institusi pendidikan termasuk salah satunya di sekolah dasar yang berbasis Agama. Sekolah Dasar berbasis agama menjadi fenomena tersendiri dikalangan masyarakat hal ini ditunjang dengan fakta yang terdapat di masyarakat bahwa tingkat kepercayaan masyarakat kepada sekolah dasar berbasis agama itu lebih besar dikarenakan pendidikan agama yang diberikan. Pendidikan Agama yang diberikan kepada anak sejak dini dalam hal ini agama Islam mampu membentuk karakter siswa sesuai dengan aqidah keislaman yang seharusnya dimiliki. Islam adalah rahmat bagi semesta Alam, sebagaimana sesuai dengan firman Allah dalam Surat al-Anbiya ayat 107 yang artinya, "Dan tiadalah Kami mengutus kamu, melainkan untuk (menjadi) rahmat bagi semesta alam". Dari ayat tersebut nampak nyata bahwa agama Islam adalah agama yang cinta dengan kedamaian, karena dengan adanya surat ini maka seorang muslim tidak boleh berbuat semenamena kepada makhluk yang berbeda keyakinan bahkan sampai dengan binatang dan tumbuhan. Oleh karenanya setiap komponen yang berbasiskan Islam harus membentuk karakter yang sesuai dengan ajaran Islam dan tentunya dengan masyarakat umum, salah satunya institusi pendidikan.

Institusi pendidikan baik negeri ataupun yang berbasis agama memiliki tanggung jawab yang sama terhadap pembentukan karakter siswanya. Hambatan yang terjadi adalah pembentukan Karakter merupakan sebuah pembelajaran yang mudah untuk diajarkan tetapi sulit untuk dilaksanakan, karena mendidik siswa terutama dalam hal pembentukan karakter siswa bukan merupakan hal yang mudah. Mendidik adalah sesuatu yang kompleks ,"Educating is a complex task that is subject to both internal influences to the educational process (social, cultural, family contexts ...) and external ones (make up our professional heritage)"( Rodríguez, Riaza, \& Gomez, 2017)

Oleh karenanya dibutuhkan peran guru yang optimal dalam menguatkan karakter kebangsaaan yang dimiliki oleh siswa di dalam setiap pelaksanaan proses pembelajaran. Peran atau fungsi dari seorang guru yakni "........as a socializing agent by providing the intellectual and social experiences from which children develop the skill, knowledge, interest, and attitudes that characterize them as individuals and that shape their abilities to perform adult roles"(Berns, 2004).

Berdasarkan latar belakang dan kajian literatur di atas maka dapat dirumuskan masalahnya adalah bagaimanakah peran guru dalam penguatan karakter kebangsaan di sekolah dasar berbasis agama dan dari perumusan masalah maka tujuan penulisan dalam penelitian ini adalah untuk mendeskripsikan peran guru dalam penguatan karakter kebangsaan di sekolah dasar berbasis agama.

\section{METODE}

Pendekatan yang digunakan dalam penelitian ini adalah kualitatif. Dalam penelitian kualitatif, peneliti adalah instrumen kunci (researcher as key instrument) yang berarti para peneliti kualitatif harus mengumpulkan sendiri data melalui dokumentasi, observasi perilaku, dan wawancara dengan para partisipan(Creswell, 2016) .Penggunaan pendekatan ini dikarenakan data yang dikumpulkan dalam penelitian ini merupakan data deskripsi seperti perilaku dan persepsi. Data yang digunakan dalam penelitian ini adalah data primer yang didapatkan langsung dari objek penelitian dan data sekunder yang didapatkan melalui studi literasi. Data primer dalam 
penelitian ini dilakukan dengan melakukan studi lapangan selama beberapa waktu yakni sejak tanggal 5-22 Januari 2018 berupa proses perizinan sampai dengan pengambilan data selesai atau jenuh.

Subjek dari penelitian ini adalah guru dan siswa kelas IVC SD Muhammadiyah 3 Nusukan Kota Surakarta yang merupakan salah satu sekolah dasar favorit dan unggulan di Kota Surakarta dengan Akreditasi A. Teknik pengambilan data yang digunakan dalam penelitian ini adalah observasi partisipatif yang dilakukan dengan mengikuti pelaksanaan segala bentuk kegiatan kelas IV C SD Muhammadiyah 3 Nusukan sejak tanggal 5 sampai dengan 22 Januari 2018, selain observasi juga dilakukan kegiatan wawancara secara mendalam kepada Kepala sekolah, guru kelas, dan siswa terkait pelaksanaan pembelajaran, dan penelitian ini juga menggunakan kuisioner yang ditujukan kepada orang tua dan siswa terkait dengan pelaksanaan pembelajaran, serta dokumentasi selama proses penelitian. Teknik Analisis data yang digunakan dalam penelitian ini adalah Analisis interaktif Miles dan Huberman yang didalamnya terdapat 4 tahapan yakni pengumpulan data, reduksi data, penyajian data dan diakhiri dengan menyimpulkan data (Miles \& Huberman, 2007)

\section{Hasil Penelitian}

\section{HASIL DAN PEMBAHASAN}

\subsection{Peran Guru dalam Pembelajaran}

Guru sebagai ujung tombak dalam pelaksanaan pendidikan merupakan pihak yang berpengaruh dalam proses pembelajaran. Kepiawaian dan kewibawaan guru sangat menentukan kelangsungan proses belajar di kelas maupun efeknya di luar kelas. Guru harus pandai membawa siswanya kepada tujuan yang hendak dicapai. Ada beberapa hal yang membentuk kewibawaan guru, antara lain: penguasaan materi yang diajarkan, metode mengajar yang sesuai dengan situasi dan kondisi siswa, hubungan antar-individu baik dengan siswa maupun antar sesama guru dan unsur lain yang terkait dalam proses pendidikan seperti administrasi, kepala sekolah, dan tata usaha serta masyarakat sekitarnya, pengalaman dan ketrampilan guru itu sendiri (Susanto, 2016).

Guru juga dimaknai sebagai orang tua kedua setelah orang tua kandung, karena sebagian besar akivitas siswa di dalam pelaksanaan pembelajaran di sekolah, gurulah yang bertanggung jawab. Guru memiliki peran untuk mengembangkan semua kompetensi siswa termasuk bagaimana dia bertingkah laku di dalam kehidupan karena itu merupakan salah satu capaian utama dari pembelajaran."To investigate the relationship between authoritative parenting style and emotional intelligence among students of bivariate Pearson correlation test findings indicate a significant relationship between Authoritative parenting style and emotional intelligence among student's spatially strong relations with girls. Zabihullah and colleagues (2012) investigate the relationship with perceived parenting styles and EI and self-handicapping reached the conclusion that the perceived parenting styles and components of emotional intelligence, strength and style Efficiency of excitement in people is the most important predictor of self-handicapping. Which is in line with our results. Dr. Dhanajay Joshi1 and Indrajeet Dutta (2015) do the same research on Indian children, the result indicated that authoritative parenting style was not all correlated with emotional intelligence of the boys, girls or students. Though, some components were correlated with emotional intelligence among girls were studied"(Samira Salimynezhad, Nahid Yusef Poor, Asma Valizade,. 2015).

Dari beberapa penelitian tersebut didapatkan hasil bahwa pola asuh orang tua yang berwibawa dalam hal ini guru ketika guru menjalankan peran sebagai orang tua akan berdampak pada kemampuan siswa dalam mengolah kemampuan emosional. Maknanya adalah kewibawaan yang diimplementasikan dengan pemberian contoh kepada siswa sekolah dasar akan berdampak baik bagi pembentukan karakter siswa. 
Guru juga memiliki peran untuk memfasilitasi siswa dalam membangun nilai-nilai moral yang ada dengan cara memberikan sudut pandang yang sesuai dengan yang diharapkan membentuk moralitas yang baik, hal ini senada dengan "........knowledge about moral values is personally constructed through a process of weighing evidence from different points of view including those of children"(Brownlee, Syu, Mascadri, Cobb-Moore, Walker, Johansson, Boulton-Lewis, dan Ailwood, 2012).

Dari pemaparan yang telah dijelaskan, maka disinilah letak urgensi dalam pelaksanaan pembelajaran di Sekolah Dasar. Karena segala sesuatu yang terkait dengan pembelajaran yang ada di dalam kelas terkait dengan performa guru dalam memberikan pembelajaran kepada siswanya. Guru memiliki peran yang vital dalam ketercapaian hasil belajar siswa. Peran guru dalam pelaksanaan pembelajaran adalah pada saat proses pembelajaran di dalam kelas dan diluar kelas. Pembelajaran yang menjadi tanggung jawab guru bukan hanya ketika menyampaikan materi di dalam kelas tetapi juga dalam kehidupan sehari-hari. Guru harus menjadi orang tua kedua bagi siswa ketika berkomunikasi di dalam sekolah, sehingga secara tidak langsung sebenarnya guru memilki peran yang penting dalam tahapan proses perkembangan seorang siswa baik dari segi materi keilmuan dan karakter sosial ketika nantinya hidup di dalam masyarakat.

\subsection{Peran Guru dalam memperkuat Karakter Kebangsaan di Sekolah Berbasis Agama}

Terdapat beberapa peranan guru di dalam upaya memperkuat karakter kebangsaan di sekolah dasar berbasis agama yakni :

1.2.1 Guru memberikan menerapkan karakter kebangsaan dalam kehidupan seharihari sebagai contoh

Berdasarkan hasil observasi yang dilakukan selama 85 jam pelajaran didapatkan data bahwa guru telah memberikan contoh-contoh implementasi dari karakter kebangsaan dalam kehidupan sehari-hari. Sesuai dengan observasi yang dilakukan guru menunjukkan kedisiplinannya terutama perihal waktu yakni ketika waktu masuk sekolah sekitar pukul 7.30 dan ketika masuk ke kelas setelah jam istirahat. Hal ini sesuai dengan informasi yang di dapat bahwasannya

"setiap pagi sekitar pukul 7.10 sampai dengan 7.25 diadakan pengarahan oleh bapak Kepala Sekolah, hal ini seperti sebuah supervisi yang dilakukan untuk mengotrol kegiatan para guru"(Wawancara Guru 10 Januari 2018)

Diluar adanya kegiatan pengarahan dari kepala sekolah guru tetap masuk ke sekolah tepat waktu dan apabila terjadwal melakssiswaan piket maka guru pun ikut menyambut kedatangan siswa dengan hangat di gerbang sekolah sambil sesekali berkomunikasi dengan orang tua siswa dan siswa. Saat pembelajaran didalam kelas guru terbiasa untuk memberikan kesempatan kepada siswa untuk menyampaikan pendapatnya, hal ini sesuai dengan informasi yang diperoleh yakni

"pembentukan karakter yang saya lakukan dengan memberikan contoh kasus yang terjadi di masyarakat lalu mengajak siswa berdiskusi bagaimana seharusnya" (Wawancara guru 10 Januari 2018)

Dalam pelaksanaan pembelajaran guru membiasakan siswa untuk berdoa terlebih dahulu sebelum memulai pembelajaran serta membaca Surat Al Fatihah, Asmaul Husna, dan melakukan hafaan surat (Murojoah). Tidak hanya itu guru juga tidak pernah menyalahkan siswa karena jawaban yang diberikan salah atau pendapat yang disampaikan kurang tepat melainkan guru tetap mengapresiasi jawaban dari siswa walaupun salah dan memberikan pengarahan agar jawaban dari siswa terarah.

Ketika sesi diskusi terkadang guru juga mengajak siswa untuk bertanya-tanya lebih dalam lagi tentang contoh kasus yang sedang didiskusikan. Seperti memberikan pertanyaan bagi diri sendiri namun seraya mengajak siswa untuk berfikir dan merefleksi lebih dalam. Guru dalam pelaksanaan pembelajaran juga rajin mengajak 
siswa untuk mengerjakan soal terutama ketika mata pelajaran Matematika. Hal ini sesuai dengan informasi yang diberikan oleh guru bahwa

"Khusus untuk mata pelajaran matematika, saya sering mengajarkan kepada siswa untuk rajin mengerjakan latihan soal, karena dengan latihan soal siswa akan terbiasa untuk mengerjakan (wawancara guru 10 Januari 2018)"

Tetapi bukan dalam artian guru hanya memberikan metode latihan soal kepada siswa lalu guru duduk dan melihat melainkan guru tetap memberikan pendampingan kepada siswa tetapi bukan maksud untuk memberikan jawaban. Guru berusaha membiasakan siswa untuk bekerja keras dalam pelaksaan di dalam pembelajaran. Dalam hal kebersihan kelas guru membuatkan jadwal piket untuk siswa tetapi guru juga turut serta dalam menjaga kebersihan lingkungan kelas yang menjadi tempat belajar.

Selain didalam pelaksanaan program pembelajaran sesuai dengan program sekolah maka terdapat program salat sunah antara jam 09.00 sampai dengan jam 10.00, berdasarkan hasil obervasi guru ikut melakssiswaan dan mendampingi siswa ketika melakssiswaan salat sunah tersebut. Di waktu yang lain guru juga ikut bersama siswa melaksanakan salat berjamaah ketika waktu salat wajib dhuhur dan ashar tiba. Hal ini merupakan program sekolah yang dimaksudkan untuk membiasakan siswa disiplin dalam beragama dan taat kepada pencipta dan guru juga ikut melakssiswaan program ini untuk menunjukkan kepada siswa.

1.2.2 Menyediakan Media Komunikasi efektif antara siswa dengan Orang tua

Berdasarkan hasil observasi yang dilakukan guru melakukannya perannya untuk membantu siswa dalam melakukan komunikasi dengan orang tua dengan menggunakan buku penghubung. Hal ini disampaikan oleh informan sebagai berikut:

"Setiap hari Buku Penghubung akan dikumpulkan agar terlihat orang tua yang mendampingi dengan membubuhkan tanda tangan di Buku Penghubung" (Wawancara dengan guru, 10 Januari 2018)

Guru mengungkapkan bahwa dengan adanya buku penghubung ini merupakan sarana yang tepat bagi guru untuk melakukan komunikasi dengan orang tua siswa dengan melibatkan siswa didalamnya.Maksud guru dengan adanya buku penghubung guru dapat berkomunikasi dengan orang tua siswa tentang perkembangan siswa baik dari segi pengetahuan misalkan pemberian tugas rumah ataupun perihal tingkah laku siswa di sekolah, sehingga orang tua menjadi mengetahui perkembangan proses belajar siswa di sekolah. Hal ini sesuai dengan informasi yang diberikan bahwa

"Siswa terkadang malu atau takut untuk menceritakan tentang kejadian di sekolah, atau mungkin karena faktor kesibukan orang tua, sehingga dengan adanya buku penghubung ini diharapakan ada moment atau kesempatan bagi siswa untuk menceritakan kejadian disekolah"(Wawancara dengan guru 10 Januari 2018)

Guru juga dalam peran untuk memberikan pendidikan informal bagi siswa melalui buku penghubung agar siswa mendapatkan perhatian dan kasih sayang di dalam proses pelaksanaan pembelajaran. Hal ini sesuai dengan informasi yang diberikan bahwa

"Siswa membutuhkan pendampingan dari orang tua dalam pembelajaran dirumah, sehingga dengan adanya buku ini diharapkan siswa mendapatkannya"(Wawancara dengan guru, 10 Januari 2018)

Pendampingan yang dibutuhkan siswa dapat diperoleh dengan adanya buku penghubung yang memebrikan ruang kepada siswa untuk berkomunikasi dengan orang tua.

\subsubsection{Melakukan pengawasan terhadap setiap perilaku siswa}

Guru juga memiliki fungsi untuk melakukan pengawasan terhadap kemajuan hasil belajar siswa, termasuk di dalamnya adalah pembentukan karakter. Berdasarkan hasil observasi guru setiap pagi selalu menanyakan kepada siswa tentang aktivitas 
salat Subuh. Hal ini bertujuan untuk melatih tanggung jawab, kejujuran, religiusitas, dan kedisiplinan siswa. Melalui aktivitas bertanya seperti ini guru akan mengetahui sejauh mana hasil pembelajaran selama ini terutama terkait dengan pembentukan karakter kebangsaan. Hal ini sesuai dengan penjelasan dari informan bahwa

"Dengan melakukan tanya jawab terkait salat dan budaya piket dikelas, saya bisa mengetahui sejauh mana karakter yang dimiliki oleh siswa" (wawancara dengan guru 10 Januari 2018)

Aktivitas yang dilakukan oleh siswa dalam kegiatan sehari-hari menjadi penilaian bagi guru termasuk cara berpakaian, cara bertutur kata, melaksanakan salat, hafalan yang dimiliki siswa, serta tanggung jawab siswa dalam mengikuti pelaksanaan pembelajaran. Pengawasan yang dilkukan guru juga melibatkan siswa sebagai evaluator bagi siswa yang lain yang nantinya akan memberikan laporan kepada guru.

\section{Pembahasan}

Guru memiliki peranan yang penting dalam pelaksanaan pembentukan karakter kebangsaan karena intensitas interaksi yang sering dengan dengan siswa, sehingga secara hubungan kedekatan guru akan mampu memberikan pengaruh dalam hal pembentukan karakter kebangsaan. Guru juga merupakan teladan bagi siswa baik dari segi pengetahuan ataupun hal-hal yang terkait dengan kepribadian karena guru merupakan agen sosial. Guru merupakan contoh bagi siswa karena siswa sekolah dasar masih memiliki pemikiran bahwa guru adalah sumber kebenaran dan siswa sekolah dasar lebih cenderung untuk meniru karena sifat imitasi yang dimiliki. Guru sebagai contoh merupakan pemikiran dari Ki Hajar Dewantara yakni "Ing Ngarsa Sung Tuladha" pemikiran dari tokoh bangsa seperti ini yang seharusnya menjadi acuan dalam pelaksanaan pembelajaran.

Hasil penelitian menunjukkan bahwa bahwa warisan luhur budaya lokal dan khazanah pemikiran tokoh pendidikan pra dan awal kemerdekaan yang mencerminkan semangat zaman (zetgeist) melawan imperialisme dan menekankan pentingnya kemandirian masih sering terasing di tanah kelahirannya (Gopinathan, 2006; Bates, R. 2008). Berdasarkan temuan yang ada maka sebenarnya apabila pemikiran ini terasing tentunya tidak melainkan tersamar karena data menunjukkan guru sudah berperan sebagai contoh didalam pelaksanaan pembelajaran dalam mengimplementasikan nilainilai karakter kebangsaan seperti religius, toleransi, disiplin, kerja keras, demokratis, rasa ingin tahu, semangat kebangsaan, bersahabat komunikatif, gemar membaca, tanggung jawab, dan peduli terhadap lingkungan.

Guru berperan menjadi contoh bagi siswanya oleh karenanya guru harus bisa menjaga dirinya sendiri karena aktivitas, kepribadian, dan kebiasaan guru. Terjadinya kegagalan guru dalam menumbuhkan karakter siswa didiknya, disebabkan seorang guru yang tak mampu memperlihatkan dan menunjukkan karakter sebagai seorang yang patut di dengar dan diikuti (Anwar Sumarsih, 2014). Hal ini sebenarnya telah disinggung oleh Ki Hajar Dewantara melalui sebuah akronim yang populer di lingkungan masyarakat Indonesia yakni digugu dan ditiru.

Hakikatnya peran guru dalam hal ini bukan hanya sebagai penyampai konsep tentang karakter kebangsaan tetapi lebih kepada pemberian contoh secara nyata, yakni dari guru sendiri yang melaksanakan konsep yang diajarkan. Hal ini sesuai dengan pendapat bahwa mengubah karakter adalah mengatur ulang kepribadian (Cronbach, 1977). Pelajaran kecil tentang prinsip-prinsip perilaku baik tidak akan efektif jika tidak terintegrasi dengan sistem kepercayaan orang tentang dirinya sendiri, tentang orang lain, dan tentang kebaikan masyarakat". Oleh karenanya untuk menyentuh sisi psikologis siswa dan mengintegrasikan karakter kebangsaan dengan sistem kepercayaan siswa maka guru harus memberikan suri tauladan yang baik sesuai dengan karakter yang diharapkan. Karena pada dasarnya pendidikan karakter adalah pendidikan nilai-nilai yang melibatkan aspek pengetahuan (kognitif), perasaan, dan tindakan (Pane Murty Magda \& Rina Patriana, 2016), sehingga peran guru 
memiliki urgensi yang begitu kuat untuk membentuk karakter siswa melalui pendidikan karakter. Lebih dipertegas bahwa "Teachers have the biggest responsibility in students'internalizing positive character traits" (Ülgera Mehmet, Süleyman Yiğittir, \& Orhan Ercan, 2014).

Peran guru selain sebagai contoh yakni melakukan komunikasi efektif dengan orang tua siswa terkait dengan perkembangan siswa baik dalam hal pemerolehan pengetahuan ataupun penguatan karakter kebangsaan. Komunikasi merupakan hal yang penting dan mendasar di dalam pelaksanaan pembelajaran. Media yang digunakan dalam berkomunikasi dengan orang tua adalah penggunaan buku penghubung. "Communication between the adult participants was formal (meetings, reports, emails, assessments, applications) and informal (conversations)" (Taylor Helen Bourke, Claire Cotter, Lindy Johnson, \& Aislinn Lalor, 2018). Buku penghubung merupakan bentuk laporan hasil pemerolehan siswa dalam belajar di sekolah serta kontrol bagi guru terhadap kinerja siswa di rumah.

Selain sebagi cara guru untuk berkomunikasi dengan orang tua siswa, buku penghubung juga memberikan ruang kepada siswa untuk menceritakan setiap hal yang dialami di sekolah. Hal ini bertujuan untuk membiasakan siswa untuk berkomunikasi dengan orang tua secara nyata dan mendalam tanpa ada yang ditutupi, a key feature of "exploratory talk"(Barnes, D. 1976). Siswa terkadang juga kesulitan untuk memulai pembicaaran dengan orang tua, oleh karenanya dengan adanya buku penghubung akan dapat dijadikan motif bagi siswa. "Motives can be defined as students own reasons for talking to their instructors" (Martin, M. M., Myers, S. A., \& Mottet, T. P, 1999). Keberadaan buku penghubung memberikan dampak yang baik dalam penguatan karakter kebangsaan siswa seperti kejujuran, tanggung jawab, dan mandiri.

Peran lain yang dilakukan oleh guru adalah melakukan pengawasan kepada perkembangan siswa terutama dalam penguatan karakter kebangsaan, karena memang pada dasarnya perkembangan karakter kebangsaan siswa ini menjadi prioritas dalam pelaksanaan kebijakan pendidikan di Indonesia. Pengawasan yang dilakukan oleh guru merupakan sebuah cara guru untuk berkomunikasi dengan siswa, hal ini bertujuan untuk mengukur sejauh mana tingkat ketercapaian karakter kebangsaan yang dimiliki oleh siswa. Fenomena ini sering disebut sebagai segitiga pedagogik, "As students of communication and composition will recall, the rhetorical triangle definesthe interdependent relationship of the speaker (or ethos), the audience (pathos) and the message (logos)" (Friesen Norm \& Richard Osguthorpe, 2018). Selain itu guru juga melibatkan siswa dalam melakukan pengawasan kepada siswa yang lain yang berdampak positif bagi penguatan karakter kebangsaan di dalam kelas. Partisipasi siswa juga merupakan hal yang dapat membaut suasana di dalam pelaksanaan pembelajaran menjadi kondusif dan nyaman, "Increased convenience can be attributed to involving student participation in important outcomes" (McKeachie, W. J. 1970). Bentuk kerjasama dengan siswa ini penting dilakukan oleh guru untuk meningkatkan profesionalitasnya "Collaboration and cooperation are regarded as key factors in professional development"(Gellert, U, 2008). Ketika Profesionalitas guru meningkat tentunya peran dari guru dalam menguatkan karakter kebangsaan juga optimal.

\section{SIMPULAN}

Berdasarkan dari hasil penelitian guru memiliki peran yang sangat vital tentang pembentukan karakter kebangsaan tidak terkecuali di lingkungan sekolah berbasis agama. Beberapa upaya yang dilakukan oleh guru untuk menanamkan karakter kebangsaan di sekolah berbasis agama yakni 1) Guru memberikan menerapkan karakter kebangsaan dalam kehidupan sehari-hari sebagai contoh, 2) Menyediakan 
Media Komunikasi efektif antara siswa dengan Orang tua, 3) Melakukan pengawasan terhadap setiap perilaku siswa.

\section{DAFTAR PUSTAKA}

Ana Iglesias Rodríguez, Blanca García Riaza, María Cruz Sanchez Gomez. (2017). Collaborative learning and mobile devices: An educational experience in Primary Education. Computers in Human Behavior (2017) 664- 677

Anggraini Purwati \& Tuti Kusniarti. (2016). The Implementation of Character Education Model Based on Empowerment Theatre for Primary School Students. Journal of Education and Practice. Vol.7, No.1 26-29

Anwar Sumarsih. (2014). Pendidikan Karakter di Madrasah Ibtidaiyah Modern Sahid, Bogor, Jawa Barat. Jurnal Edukasi Volume 12 Nomor 3 hal 323-337

Barnes, D. (1976). From communication to curriculum. Harmondsworth: Penguin Books

Bates, R. (2008). Teacher Education in Global Context: Towards a Defensible Theory of Teacher Education. Journal of Education of Teaching. 34(4), 277-293.

Berns, R.M. (2004). Child, Family, School, Community Socialization and Support. Sixth Edition. Australia: Thompson Learning. Inc.

Brownlee, Jia-Jia Syu, Julia Mascadri, Charlotte Cobb-Moore, Sue Walker, Eva Johansson, Gillian Boulton-Lewis, dan Jo Ailwood . (2012). Teachers' and children's personal epistemologies for moral education: Case studies in early years elementary education. Journal Teaching and Teacher Education 28 (2012) $440-450$

Creswell, J.W. (2016). Research Design Pendekatan Metode Kualitatif, Kuantitatif, dan Campuran Edisi 4. Terj. Achmad Fawaid dan Rianayati Kusmini Pancasari. Yogyakarta: Pustaka Pelajar.

Cronbach, Lee J. (1977). Educational Psychology 3rd edition. New York: Harcourt Brace Jovanovich Inc

Gellert, U. (2008). Routines and collective orientations in mathematics teachers' professional development. Educational Studies in Mathematics, 67, 93-110

Gopinathan. (2006). Challenging the Paradigm: Notes on Developing an Indigenized Teacher Education Curriculum. Improving Schools, 9(3), 261-272.

Friesen Norm \& Richard Osguthorpe. 2018. Tact and the pedagogical triangle: The authenticity of teachers in relation. Teaching and Teacher Education (70) 255264

Lickona, T. (1992). Educating for Character, How Our School Can Teach Respect and Responsibility. New York: Bantam Books

Martin, M. M., Myers, S. A., \& Mottet, T. P. (1999). Students' motives for communicating with their instructors. Communication Education, 48, 155-164. https://doi.org/10.1080/03634529909379163

Miles, Mattew B dan Amichael Huberman. (2007). Analisis Data Kualitatif Buku Sumber tentang Metode-Metode Baru. Terjemahan Tjetjep Rohendi.Rohisi. Jakarta: Universitas Indonesia.

McKeachie, W. J. (1970). Research on college teaching: A review. Washington, DC: Eric Clearinghouse on Higher Education

Meyer, K. R., \& Hunt, S. K. (2011). Rethinking evaluation strategies for student participation. Basic Communication Course Annual, 23, 93-126.

Pane Murty Magda \& Rina Patriana. (2016). The Significance of Environmental Contents in Character Education for Quality of Life. Procedia - Social and Behavioral Sciences 222 , pp $244-252$

Samira Salimynezhad, Nahid Yusef Poor, Asma Valizade,. (2015). The Studies of Relationship between Parental Styles with Emotional Intelligence in Elementary 
Schools Students of MAKOO, Procedia - Social and Behavioral Sciences, Volume 205, , Pages 221-227, ISSN 1877-0428

Taylor Helen Bourke, Claire Cotter, Lindy Johnson, Aislinn Lalor. (2018). Belonging, school support and communication: Essential aspects of school success for students with cerebral palsy in mainstream schools. Teaching and Teacher Education 70 153-164

Susanto, Ahmad. (2016). Teori Belajar dan Pembelajaran di Sekolah Dasar. Jakarta: Prenadamedia Group

Ülgera Mehmet, Süleyman Yiğittir, \& Orhan Ercan. (2014). Secondary School Teachers' Beliefs On Character Education Competency. Procedia - Social and Behavioral Sciences $131442-449$. 